\title{
Prosodic effects on vowel spectra in three Australian languages
}

\author{
Simone Graetzer, Janet Fletcher, John Hajek \\ Phonetics Laboratory, School of Languages and Linguistics, University of Melbourne \\ \{simone.graetzer, j.fletcher, j.hajek\}@unimelb.edu.au
}

\begin{abstract}
In this paper, the spectral properties of vowels in three Australian languages are examined with the aim of determining whether prosodic prominence and domain-edge effects on formant frequencies, formant variability and vowel space dispersion can be identified. It is shown that these vowel systems are sufficiently dispersed, with an anchoring of the system by the open central vowel. It is also shown that for Burarra but not for Gupapuyngu or Warlpiri there is some evidence of prosodically-driven hy per-articulation. Finally, the data indicate pre-boundary lengthening in all three languages, which in some cases appears to be associated with changes in vowel quality.
\end{abstract}

Index Terms: vowel, vowel space, variability, acoustics, dispersion, duration, Australia

\section{Introduction}

The focus of this paper is on vowel spectra and the systemic variability and dispersion of vowels in disyllabic words in three Australian languages: Burarra, Gupapuyngu and Warlpiri. The paper addresses the interaction and effects of factors such as vowel quality, and prosodic prominence and position in the prosodic domain (word-final or pre-boundary, and word-medial).

\subsection{Adaptive Dispersion Theory}

Adaptive Dispersion Theory (DT) proposes that vowel contrasts are systemic and relational rather than local and absolute [1]. Each vowel acts as a repeller in a dynamic system. As such, it was originally claimed that adjacent vowels should be roughly equidistant in a system, i.e., (perceptual) vowel contrasts should be maximal, and the acoustic distance between adjacent vowels should reduce as the system size increases. DT also predicted that languages with the same vowel system will exhibit identical F1 distances between adjacent vowels. However, the maximal contrast hypothesis was later modified by Lindblom [1] to allow for the possibility of merely sufficient dispersion, emphasizing sufficient contrast combined with economy of effort. A number of previous analyses of Australian languages, including Burarra and Warlpiri, have indeed found that these vowel spaces are sufficiently, rather than maximally, dispersed [2] [3].

\subsection{Prosodic effects on vowel realisation}

In commonly studied languages such as English, prosodically prominent vowels are typically less variable and more peripheral in the F2 x F1 space than prosodically weak vowels. Vowels at higher levels of prosodic prominence tend to be produced with greater acoustic expansion or peripherality or with more extreme gestures [4] - [6]. For example, in English, accented /i/ tends to be produced with a more anterior constriction than unaccented /i/ [5], while in French, the stronger the prosodic boundary associated with the vowel /a/, the higher the F1 frequency [7]. Furthermore, prosodic domain-initial (e.g., phrase-initial) positions seem to be 'generally characterised by more "forceful" articulatory gestures' [8] (p. 232). This type of behaviour has been termed prosodically driven 'hyper-articulation' [4] [9]. Typically, vowels are associated with less variability and greater dispersion when prosodically prominent, as part of an overall articulatory expansion of prominent syllables [4] [10]. Stressed vowels are also typically more resistant to coarticulation by adjacent segments than are unstressed vowels [9] [11]. Additionally, there are prosodic domain-final effects on vowels: pre-boundary or phrase-final lengthening can occur [12].

In the context of Australian languages, Burarra vowels are known to undergo some magnitude of vowel reduction in unstressed syllables [13]. In older speakers of the Central Australian language, Arrernte, the low central vowel appears to involve a higher F1 (increased openness) when stressed [14]. In other Australian languages, little evidence has been found of the predicted effect of prosodic prominence on vowels in the F2 x F1 plane, but there is some evidence of an effect of pre-boundary or phrase-final position on vowel realisation. Some vowels in some Australian languages are longer and more peripheral in phrase-final positions [3], while others are lengthened phrase-finally but do not change in quality [14] [15]. In their study of Bininj Gun-wok and Dalabon, Fletcher and Butcher [16] did not find evidence of reduced vowel peripherality in phrase-final position, perhaps due to duration-related expansion of the vowel space in this position. Similarly, Fletcher and Butcher [3] found for a female speaker of another three vowel language with a length distinction, Kayardild, that close vowels tended not to show effects of prosodic context but rather of vowel length phrasefinally (or an interaction between such prosodic effects and length). In Kunwinjku, there is an effect of prosodic prominence on variability, which is greater in unaccented vowels [17]. Finally, in Warlpiri, it appears to be the medial consonant rather than the prominent vowel that undergoes medial strengthening (and lengthening), and this consonant may carry stress [18].

\subsection{Research questions and parameters}

In the current paper, we set out to determine how vowels in Burarra, Gupapuyngu and Warlpiri differ in F1 and F2 in disyllabic CV1CV2 words. Secondly, we wanted to examine whether vowels differ in F1 and F2, formant variability and vowel space dispersion according to prosodic prominence and to position in the word (V1 or V2). Finally, we wanted to determine whether there is any effect of vowel position on vowel duration in the three languages. As all three vowel systems are relatively small, the issue of an effect of inventory size on variability or dispersion is not addressed here; see [19]. Of the languages considered here, Burarra is a non-PamaNyungan language and Gupapuyngu and Warlpiri are members of the Pama-Nyungan family, which includes most 
indigenous Australian languages. Burarra and Gupapuyngu are spoken in central and north-eastern Arnhem Land, respectively, and Warlpiri is spoken to the north-west of Alice Springs. These languages have many place and few manner consonantal contrasts and small vowel inventories. Gupapuyngu and Warlpiri have three vowels with a length contrast, while Burarra has five vowels: $/ \mathrm{i} /, / \varepsilon /, / \mathfrak{v} /$ (hereafter 'a'), $/ \mathrm{o} /$ and $/ \mathrm{u} /$.

\section{Methods}

The subjects of this study were nine adult female speakers of Burarra (speakers DP, KF, MW), Gup apuyngu (AM, BT, EG) and Warlpiri (BP, KR, RR) aged between 30 and 65 . Typically, three tokens of each word type were elicited. The corpus was collected and digitised by Andrew Butcher. To avoid effects of gender, we limited our analysis to the data available for female speakers in the corpus. All acoustic measurements were carried out in the EMU Speech Database System [20]. The onsets of the vowels were marked at the onset of periodicity and the offsets at the offset of periodicity. $\mathrm{F} 1$ and $\mathrm{F} 2$ values were measured at the vowel midpoint. All relevant segmentation procedures are described in full by Graetzer [19]. The prosodic prominence of vowels was determined on the basis of published prosodic descriptions, e.g., [13] [18], an auditory impressionistic analysis and an acoustical analysis; we assumed that the vowel carrying a sharp F0 rise to a peak somewhere in or around the syllable rhyme was accentually prominent. Main stress was wordinitial in these data. Words were associated with post-lexical (or phrasal) prosodic prominence; therefore, prosodic effects applying to both the utterance/phrase level and the word level were relevant. Statistical and graphical procedures were run in $\mathrm{R}$ version 2.14.0 [21] using the EMU-R package. F1 and F2 frequencies $(\mathrm{Hz})$ were extracted from the vowel midpoint $\left(\mathrm{V} 1_{\mathrm{MID}}\right.$ and $\mathrm{V} 2_{\mathrm{MID}}$ ) in CV1CV2 words, in which $\mathrm{V} 1$ is prominent and V2 is not. In order to compare vowel systems in the three languages, formant frequencies were submitted to the normalisation procedure used in similar studies in the context of vowels [22]: Nearey vowel-extrinsic normalisation [23]. This procedure was conducted on the raw F1 and F2 data by means of a formula and function outlined by Harrington [24]. The distribution of the vowel categories is given in Table 1 (note that no long vowels were present for Warlpiri; however, short and long Warlpiri vowel counterparts have been found to be similar in quality [25]; note also differences in Burarra distribution between V1 and V2). Linear Mixed Model (LMM) procedures were used for investigations of $\mathrm{F} 1$ and F2 frequencies, in which the effects of vowel quality and word-medial consonant place of articulation (not discussed here), language group and vowel position (V1/V2; random factor: speaker) were examined. The non-normalised F1 and F2 LMM results were then compared to the normalised results and any differences in significance levels were reported.

Euclidean distances (here termed 'distances') - acoustic straight line distances between vowels in the F2 x F1 plane were calculated after, e.g., [1] [24], as a measure of the magnitude of hyper-articulation in the vowel space. This procedure is similar to that used by Recasens and Espinosa [22]. The distances were then treated as the dependent variable in an LMM, with the fixed factors of language group and vowel position (random factor: speaker). Levene-type t-tests applied to deviations of observations from the median were run per speaker and formant (F1 and F2) to test for equality of variance between V1 and V2 for Gupapuyngu and Warlpiri, which have three vowel qualities in V1 and V2 position, but not for Burarra, as it has five vowel qualities in V1 position and only three in V2. Wilcoxon signed rank tests for paired samples were calculated for V1 and V2 durations per speaker in order to determine whether there was lengthening of V1 or V2 $(\alpha=0.05)$. Pearson's product moment correlation tests were run for vowel duration and distances, i.e., vowel space expansion, collapsing V1 and V2 categories. Raw and normalised results were not compared in the context of the Levene's and Wilcoxon tests as these were intra-speaker.

Table 1. The distribution of vowels where BUR= Burarra, GUP $=$ Gupapuyngu, WAR $=$ Warlpiri.

\begin{tabular}{|c|c|c|c|c|}
\hline & V & BUR & GUP & WAR \\
\hline V1 & a & 167 & 152 & 219 \\
& a: & N/A & 107 & N/A \\
& $\varepsilon$ & 36 & N/A & N/A \\
& $\mathrm{i}$ & 66 & 48 & 102 \\
& $\mathrm{i}:$ & N/A & 50 & N/A \\
& o & 84 & N/A & N/A \\
& $\mathrm{u}$ & 97 & 110 & 124 \\
& $\mathrm{u}:$ & N/A & 87 & N/A \\
V2 & $\mathrm{a}$ & 422 & 281 & 199 \\
& $\mathrm{i}$ & 23 & 108 & 110 \\
& $\mathrm{u}$ & 5 & 165 & 136 \\
\hline
\end{tabular}

\section{Results}

\subsection{Normalised and raw F1 and F2 frequencies, variability and euclidean distances}

\subsubsection{Normalised frequencies}

In Figure 1, 95\% confidence ellipses in Nearey-normalised formant data extracted at vowel midpoints are shown per language group and vowel position (V1, L; V2, R). The typically close proximity and overlap of the vowel ellipses indicates sufficient rather than maximal dispersion. For Gupapuyngu and Warlpiri, a 'canonical' realisation of a triangular vowel space is observed, with the low central vowel as 'anchor' (see, e.g., Butcher's [2] use of this term). Gupapuyngu displayed greater dispersion than Burarra and Warlpiri in both vowel positions. For Burarra, /a/ acted as anchor in $\mathrm{V} 2$, while $/ \varepsilon /$ and /a/ were equally close to the grand centroid (' $\mathrm{X}$ ') in V1. In the F2 x F1 space, in both V1 and V2, the difference between Gupapuyngu and Warlpiri mainly involved an upwards shift but also a retraction of $/ \mathrm{i}$ a/ in Warlpiri relative to Gupapuyngu. In Warlpiri, /i u/ were realised with a lower F1 (increased closeness) than in the other languages. Within each vowel system, point vowels were similarly spaced relative to one another overall. However, when frequency distances between point vowels were compared for Gupapuyngu and Warlpiri, which have identical vowel systems, in $\mathrm{F} 1$, in $\mathrm{V} 1$ and $\mathrm{V} 2$, /a/ was closer to /i $\mathrm{u} /$ in Warlpiri than in Gupapuyngu (there was a relative reduction in the F1 range for Warlpiri), while /i u/ were similarly distant. In $\mathrm{F} 2$ in $\mathrm{V} 1$, in Gupapuyngu, /a/ was further from /i/ and closer to /u/ than in Warlpiri. F2 distances in V1 were similar in the two languages, but slightly higher (more anterior) in Gupapuyngu. Burarra vowels $/ \varepsilon \mathrm{o} /$ were approximately equidistant between 

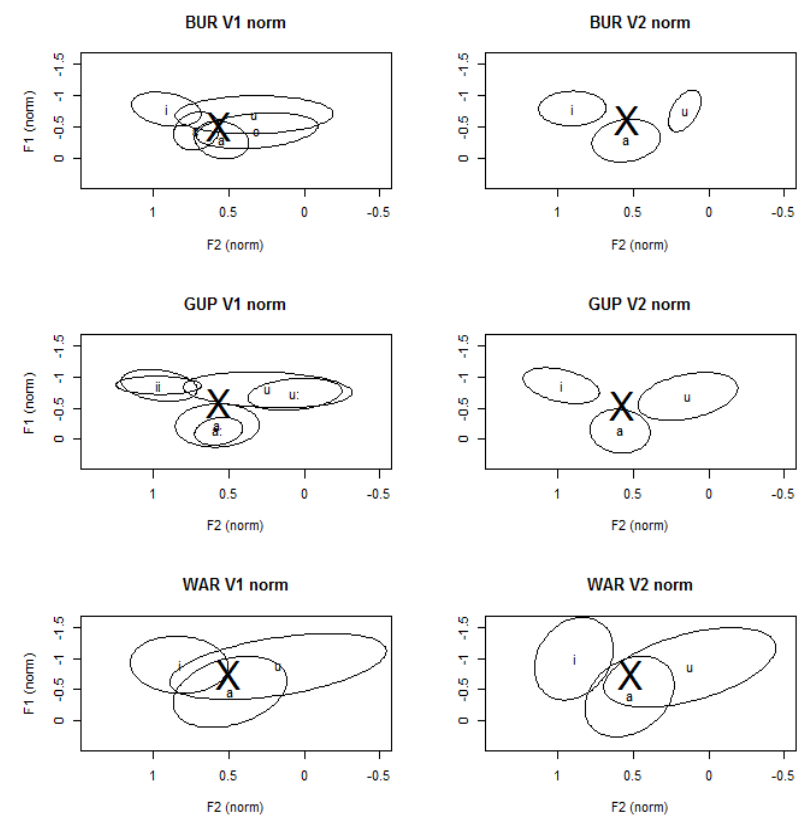

Figure 1: Nearey-normalised F2 $x F 1$ plots in V1 $(L)$ and V2 $(R)$ conditions (upper: Burarra; middle: Gupapuyngu; lower: Warlpiri); axes in Nearey units.

the open and close vowels and were very similar in height. Burarra /o u/ were very similar in $\mathrm{F} 2$, while / $/ \varepsilon /$ was much lower in F2 (less anterior) than /i/. In V2, Burarra differed from Gupapuyngu and Warlpiri in that /i/ was associated with a similar F1 to /u/, while for the other languages /i/ was associated with a much lower $\mathrm{F} 1$ than $/ \mathrm{u} /$, i.e., /i/ was a closer vowel than $/ \mathrm{u} /$ in these systems. It is clear that $/ \mathrm{u} /$ can be realised with little or no rounding given the degree of F2 variability in $/ \mathrm{u} /$ and its realisation relative to $/ \mathrm{i} a /$ in the vowel space. This is the case particularly for Burarra and Gupapuyngu in $\mathrm{V} 1$, in which position there were more $/ \mathrm{u}(:) /$ tokens in the corpus.

\subsubsection{Raw frequencies - LMM}

LMM procedures were used to investigate the effect of vowel position within the word, and thus also prosodic prominence, on $\mathrm{F} 1$ and $\mathrm{F} 2$ formant frequencies at vowel midpoints in CV1CV2 words. The factor of language group was also included in the model. In the F1 condition, Warlpiri was associated with lower frequencies than Burarra (BUR:WAR, Estimate $=-57, \mathrm{SE}=28, \mathrm{t}=-2, \mathrm{p}<0.05)$. Other comparisons were not significant. Vowels in V1 position were typically associated with slightly lower F1 values than vowels in V2 $(\mathrm{V} 2 \mathrm{~V} 1, \quad$ Estimate $=-23, \quad \mathrm{SE}=4, \mathrm{t}=-5.8, \quad \mathrm{p}<0.0001)$. This difference was located in the Gupapuyngu and Burarra data. For Gupapuyngu this pattern appears to be due to a slightly lower F1 (more close vowel) in V1 /a u/, while in Burarra it appears to be due to a lower F1 in V1/a/. For Burarra it cannot be excluded that this result is due to differing vowel distribution in V1 and V2. Tukey's post-hoc tests indicated that Gupapuyngu, like Warlpiri, was associated with lower F1 frequencies (more close vowels) than Burarra $(\mathrm{z}=-3.6$, $\mathrm{p}<0.001$ ). In a LMM analysis of F2, there was no effect of language group or vowel position. These $\mathrm{F} 1$ and $\mathrm{F} 2$ results were consistent with those for the normalised data.

\subsubsection{Variability (raw frequencies)}

Across all vowels, variability tended to be higher in magnitude in F2 - presumably because of coarticulatory effects exerted by surrounding consonants - than in F1, but particularly for /i u/ (Figure 1). Typically, close front vowels varied less than the other point vowels in F1. This was not the case in F2, in which $/ \mathrm{a} / \mathrm{varied}$ least and $/ \mathrm{u} /$ tended to vary most. With the exception of Burarra (but see Table 1), for each point vowel, F1 variability tended to be higher in V2 and F2 variability tended to be slightly higher in V1. According to Levene's tests for Gupapuyngu and Warlpiri, in F1, only one speaker of each language group produced a difference in overall variance between V1 and V2 conditions: EG and KR respectively (GUP EG, $\quad \mathrm{F}(1,194)=7.2, \quad \mathrm{p}<0.01 ; \quad$ WAR $\mathrm{KR}, \quad \mathrm{F}(1,342)=33.9$, $\mathrm{p}<0.0001$ ). In $\mathrm{F} 2$, only one speaker of Warlpiri, BP, produced a difference between conditions $(F(1,232)=9, p<0.005)$. In the three cases, V1 was associated with less variance than V2, indicating that more variability existed in the prosodically weak, word-final vowel, as would be predicted.

\subsubsection{Euclidean distances (raw frequencies)}

Across the language groups, as indicated by the distance of vowels from the grand centroid in Figure 1, /a/ tended to be associated with smaller distances of 200 to $300 \mathrm{~Hz}$, while /i/ was associated with larger distances of 520 to $775 \mathrm{~Hz}$, and /u/ was associated with intermediate to relatively large distances of 440 to $690 \mathrm{~Hz}$. In Gupapuyngu, long vowels tended to be more peripheral than short vowel counterparts. For Burarra speakers DP and MW, significantly greater dispersion occurred in V1 than V2 when all vowel qualities were included in V1 (DP, V=8844, p<0.005; MW, V=20133, $\mathrm{p}<0.05)$. The same pattern did not achieve significance for speaker KF ( $V=2928, p=0.17)$, perhaps because there were no $\mathrm{V} 2 / \mathrm{u} /$ tokens for that Burarra speaker. When vowel qualities were reduced to /i a u/ only, to facilitate comparison between $\mathrm{V} 1$ and V2, similar results were obtained (DP, W=13806, $\mathrm{p}<0.0001 ; \mathrm{KF}, \mathrm{W}=3384, \mathrm{p}=0.23 ; \mathrm{MW}, \mathrm{W}=13830, \mathrm{p}<0.05)$. This pattern of greater expansion in V1 was mainly located in /i u/. When Gupapuyngu short vowels only were considered, distances overall did not differ according to vowel position (AM, V=10414, $\mathrm{p}=0.4$; BT, $\mathrm{V}=13259, \mathrm{p}=0.11 ; \mathrm{EG}, \mathrm{V}=2449$, $\mathrm{p}=0.94$ ), which indicated a lack of vowel space expansion in V1 relative to V2. With regard to the Warlpiri speakers, there was greater dispersion in V2 for at least two speakers (BP, $\mathrm{V}=2200, \mathrm{p}<0.005 ; \mathrm{KR}, \mathrm{V}=5896, \mathrm{p}<0.05$ ), and this pattern was particularly evident in $/ \mathrm{i} \mathrm{u} /$, but the difference did not achieve significance for the third speaker, $R R(V=5646, p=0.4)$. In order to compare overall dispersion across languages, an LMM was run with the fixed factors of language group and vowel position with interactions. All main and interaction effects were significant at $p<0.005$ or below. Vowel positions differed strongly at $\mathrm{p}<0.0001(\mathrm{~V} 2: \mathrm{V} 1$, Estimate $=78, \mathrm{SE}=37$, $\mathrm{t}=8.3$ ); V1 was typically associated with larger distances; however, this difference was in fact primarily located in Burarra. Gupapuyngu was associated with most dispersion and Burarra with least, while Warlpiri dispersion was intermediate (BUR:GUP, Estimate=191, $\mathrm{SE}=52, \quad \mathrm{t}=3.7, \quad \mathrm{p}<0.0005$; BUR:WAR, Estimate $=167, \mathrm{SE}=52, \mathrm{t}=3.2, \mathrm{p}<0.005)$. These results were again consistent with those for the normalised data. 


\subsection{Vowel duration}

Typically in Burarra, /a/ was longer in duration than /i/ and /u/ by $>30 \mathrm{~ms}$. In Warlpiri, there was a trend in the same direction but in Gupapuyngu, there was little difference overall between vowels. For the majority of speakers, vowels /a i u/tended to be longer in duration in V2 position (by $40 \mathrm{~ms}$ in Burarra and Warlpiri and by $90 \mathrm{~ms}$ in Gupapuyngu, on average), indicating phrase-final or pre-boundary lengthening. For Burarra speakers DP and MW, vowel duration was greater in V2 (DP, $\mathrm{V}=2310, \mathrm{p}<0.0001 ; \mathrm{MW}, \mathrm{V}=1454, \mathrm{p}<0.0001)$. For KF, V1 and $\mathrm{V} 2$ did not vary $(\mathrm{V}=2161, \mathrm{p}=0.44)$, but recall that there were no KF /u/ tokens in V2. For all Gupapuyngu and Warlpiri speakers, durations were consistently greater in V2 at $\mathrm{p}<0.0001$. The Gupapuyngu short/long vowel distinction in V1 tended to show a 1:1.5 - 1:1.7 ratio, in which the long vowel was 1.5 to 1.7 times the length of its short counterpart. Correlations of vowel duration and distances per speaker (collapsing vowel positions) were performed to test whether expansion related meaningfully to phrase-final lengthening. Correlations were in most cases low or very low at $r<0.25$. However, four of the nine /i/ tests resulted in low to moderate correlations of $>0.4$, and two of the nine $/ u /$ tests resulted in low correlations of 0.3 . That is, under certain conditions for some speakers, there was a weak positive correlation between vowel space expansion and vowel duration; such correlations were more likely to occur for /i/ than /a u/.

Table 2. Summary of vowel position results

\begin{tabular}{|l|l|l|l|l|}
\hline Procedure & V1 & & V2 & Comment \\
\hline LMM F1 & V1 & $<$ & V2 & GUP \& BUR \\
LMM F2 & V1 & $=$ & V2 & No effects \\
Variability F1 & V1 & $=<$ & V2 & GUP \& WAR \\
Variability F2 & V1 & $=<$ & V2 & GUP \& WAR \\
Distances BUR & V1 & $>$ & V2 & Esp. in /i u/ \\
Distances GUP & V1 & $=$ & V2 & No effects \\
Distances W AR & V1 & $<$ & V2 & Esp. BP \& KR; /i u/ \\
LMM Distances & V1 & $>$ & V2 & Located in BUR \\
Duration & V1 & $<$ & V2 & Except BUR KF \\
\hline
\end{tabular}

\section{Discussion and conclusions}

Our first research question concerned how vowels in these languages differ in F1 and F2 in disyllabic CV1CV2 words. Clear evidence was provided of sufficient rather than maximal dispersion in Burarra, Gupapuyngu and Warlpiri vowel spaces, as has been found previously for Burarra [2] and other Australian languages such as Kunwinjku and Dalabon [17]. Typically, for the three languages considered here, /a/ acted as vowel space anchor or pivot. Some differences between the languages' vowel spaces became apparent. The Warlpiri normalised vowel space was found to be slightly more compact and also slightly lower in F1 (more close) than those of Gupapuyngu and especially Burarra. In Burarra, the close vowels tended to be similar in F1, but in Gupapuyngu and Warlpiri, /i/ was lower in F1 than /u/. When F1 distances between vowels were compared in Gupapuyngu and Warlpiri, which have identical vowel systems, F1 distances tended to be slightly larger in Gupapuyngu. These results disconfirm the strong version of the DT hypothesis that languages with the same vowel system will exhibit identical F1 distances between adjacent vowels. In general, /i/ tended to vary least in F1, indicating strong articulatory requirements associated with tongue dorsum raising and fronting and bracing against the hard palate [22] [26]. The finding of high variability in $/ u /$ in F2, which is typically associated with this vowel [22] [26], suggests some fronting and lip unrounding. /a/ tended to vary in both F1 (height) and F2 (anteriority). The large amount of F2 variability and overlap in these vowel spaces can be related to the 'place of articulation imperative' [13]. This constraint requires that, given few vowel contrasts and many (coronal) consonant place constrasts, cues to place are prioritised over vowel quality cues in Australian languages. The role of consonant place in vowel variability and dispersion in these languages will be investigated in future research.

The second research question was whether vowels differ according to prosodic prominence and position in the word (V1 or V2) in F1 and F2, formant variability and vowel space dispersion. Table 2 presents a summary of the relevant findings. Across languages, phrase-final vowels (V2) tended to be slightly higher in F1 (more open), but this pattern in F1 was mainly located in the Burarra data in $/ a /$, and in the Gupapuyngu data in /a u/. There were no effects in F2. Some evidence was presented for some Gupapuyngu and Warlpiri speakers of greater F1 and F2 variability in the word-final vowel, consistent with findings for Kunwinjku [17]. Given the finding of increased duration in V2 across languages, it is likely that any increased variability in V2 is due to phrasefinal lengthening rather than the absence of accentuation. Regarding dispersion, typically, for the Burarra speakers, greater dispersion occurred in the prosodically prominent vowel, consistent with previous claims that Burarra exhibits vowel reduction in unstressed syllables, i.e., V2 in this experiment [13]. For two Warlpiri speakers, greater dispersion occurred in the phrase-final, lengthened, vowel. We found in Gupapuyngu that /a u/ were slightly more open in V2 than in $\mathrm{V} 1$, indicating increased jaw opening and sonority, which is likely to be the result of lengthening. However, the effect of vowel position on overall dispersion in Gupapuyngu did not reach significance for any speaker. In general, dispersion in the vowel space was not greater in Burarra than in Gupapuyngu in V1 (or V2), despite the former language having a larger inventory size. In fact, Gupapuyngu was associated with the largest magnitude of dispersion overall. The finding that a language with a larger inventory does not necessarily show a larger magnitude of dispersion is consistent with previous findings in European languages, e.g., [22]. Regarding the question of whether there is any effect of vowel position on vowel duration, as mentioned, our results confirm that there is pre-boundary lengthening in Burarra, Warlpiri and Gupapuyngu, in accordance with observations for other Australian languages, e.g., [14]. Typically, vowel duration did not correlate with expansion. However, for some speakers, /i/ showed a weak positive correlation. Further research is needed to separate the effects of position in word and prosodic prominence and to comprehensively investigate prominence effects on word-medial consonants in these languages.

\section{Acknowledgements}

We would like to thank Andrew Butcher for providing the corpus. We would also like to thank the speakers involved. This research was funded by an Australian Postgraduate Award granted to the first author. 


\section{References}

[1] Lindblom, B., "Phonetic universals in vowel systems", in J. J. Ohala, and J. J. Jaeger [Eds.], Experimental Phonology, 13-44, Orlando, Academic Press, 1986.

[2] Butcher, A. R., "On the phonetics of small vowel systems: evidence from Australian languages", in R. Togneri [Ed.], Proceedings of the 5th Australian International Conference on Speech Science and Technology, 28-33, Canberra, Australian Speech Science and Technology Association, 1994.

[3] Fletcher, J. and Butcher, A., "Local and global influences on vowel formants in three Australian languages", in D. Recasens, M. -J. Solé, and J. Romero [Eds.], Proceedings of the 15th International Congress of Phonetic Sciences, 905-908, Barcelona, 2003.

[4] de Jong, K., "The supraglottal articulation of prominence in English: linguistic stress as localized hyper-articulation", Journal of the Acoustical Society of America, 97(1):491-504, 1995.

[5] Cho, T., "Prosodic strengthening and featural enhancement: evidence from acoustic and articulatory realisations of /a $\mathrm{u} /$ in English", Journal of the Acoustical Society of America, 117(6):2867-2878, 2005

[6] Mooshammer, C. and Fuchs, S., "Stress distinction in German Simulat ing kinematic parameters of tongue tip gestures", Journal of Phonetics, 30(3):337-355, 2002.

[7] Tabain, M., "Effects of prosodic boundary on /aC/ sequences: Acoustic results", Journal of the Acoustical Society of America 113(1):516-531, 2003

[8] Fujimura, O., "Methods and goals of speech production research", Language and Speech, 33(3):195-258, 1990

[9] Cho, T., "Prosodically conditioned strengthening and vowel-tovowel coarticulation in English", Journal of Phonetics, 32(2):141-176, 2004

[10] Beckman, M. E., Edwards, J. and Fletcher, J., "Prosodic structure and tempo in a sonority model of articulatory dynamics", in G. J. Docherty and D. R. Ladd [Eds.], Papers in Laborat ory Phonology II, 68-86, Cambridge University Press, 1992.

[11] Bombien, L., Mooshammer, C., Hoole, P. and Kühnert, B., "Prosodic and segmental effects on EPG contact patterns of word-initial German clusters", Journal of Phonetics, 38:388-403, 2010

12] Fletcher, J. and Vatikiotis-Bateson, E., "Prosody and intrasyllabic timing in French", in Proceedings of the 3rd Australian Speech Science and Technology Conference, 318-323, 1990.

[13] Butcher, A. R., "Australian Aboriginal languages: consonant salient phonologies and the "place-of-articulation imperative", in J. M. Harrington and M. Tabain [Eds], Speech Production: Models, Phonetic Processes and Techniques, 187-210, Psychology Press, 2006.

[14] Tabain, M. and Breen, G., "Central vowels in Central Arrernte: a spectrographic study of a small vowel system", Journal of Phonetics, 39(1):68-84, 2011.

[15] Bishop, J., "'Stress Accent' without Phonetic Stress: Accent Type and Distribution in Bininj Gun-wok", in Proceedings of the $1^{\text {st }}$ International Conference of Speech Prosody, 179-192, Aix-enProvence, 2002

[16] Fletcher, J. and Butcher, A. R. "Vowel dispersion in two northern Australian languages: Dalabon and Bininj Gun-Wok", in C. Bow [Ed.], Proceedings of the 9th International Conference on Speech Science and Technology, 343-348, Melbourne, 2002.

[17] Fletcher, J., Stoakes, H., Loakes, D. and Butcher, A., " Spectra and durational properties of vowels in Kunwinjku", in J. Trouvain and W. J. Barry [Eds.], Proceedings of the $16^{\text {th }}$ International Conference of Phonetic Sciences (ICPhS), 937-940, Pirrot, 2007.

[18] Butcher, A. R. and Harrington, J. M., "An acoustic and articulat ory analysis of focus and the word/morpheme boundary distinction in Warlpiri", in S. Palethorpe and M. Tabain [Eds.], Proceedings of the 6th International Seminar on Speech Production, 19-24, Sydney, 2003.
[19] Graetzer, S., An acoustic study of coarticulation: consonant vowel and vowel-to-vowel coarticulation in four Australian languages. PhD thesis, University of Melbourne, 2012.

[20] Cassidy, S. and Harrington, J., "EMU README; the EMU speech database system". Online: http://emu.sourceforge.net/, accessed on 1 Dec 2013.

[21] R Development Core Team, R: a language and environment for statistical computing, R Foundation for Statistical Computing. Online: http://www.R-project.org, accessed on 1 Nov 2013.

[22] Recasens, D. and Espinosa, A., "Dispersion and variability in Catalan five and six peripheral vowel systems", Speech Communication, 51(3):240-258, 2009.

[23] Nearey, T., Phonetic feature systems for vowels. PhD thesis, University of Alberta. Reprinted by the Indiana University Linguistics Club, 1978.

[24] Harrington, J., The phonetic analysis of speech corpora. Chichester, John Wiley and Sons, 2010.

[25] Butcher, A. R., The sounds of Australian languages. Unpublished manuscript, 1993.

[26] Recasens, D., "Lingual coarticulation", in W. Hardcastle and N. Hewlett [Eds.], Coarticulation: theory, data and techniques, 80104, Cambridge University Press, 1999. 